\title{
Symbian OS for Developing Mobile Multimedia Software Platform for Gymnastics
}

\author{
https://doi.org/10.3991/ijet.v12.i11.7864 \\ Yingbao Zhou \\ Nanjing Xiaozhuang University, Nanjing, China \\ zhouyb111@yeah. net
}

\begin{abstract}
Traditional multimedia technology is not convenient for mobile devices. Therefore, traditional teaching methods are still used in gymnastics teaching. Meanwhile, these classes can far from satisfying students' requirements for social development and learning. In this research, we designed a mobile multimedia software for gymnastics utilizing Symbian OS. This uses the wireless package switch technology and guarantee the network transmission quality for the client. We used the audio editing interfacing to improve the smooth operation of the client software based on Symbian MMF. A survey shows that the experimental group had higher satisfaction with the application of this platform and could improve their gymnastics skills.
\end{abstract}

Keywords-Symbian OS, gymnastics, mobile multimedia

\section{Introduction}

With the popularization of internet, new technologies on information, communication, computer and others have emerged continuously, and the wireless mobile communication has been used more and more widely in various walks of life [1]. The contemporary world has been transformed into one that is basically based on information and the information flow speed is positively correlative to its social value. At this moment, the information media play an important role, and the emergence of mobile multimedia brings great convenience to the modern society [2]. Mobile multimedia are the portable mobile devices which are the integration of the computer and video technique to realize the information communication and transmission between human and computer on two or above media [3]. Simply, a mobile phone that people use is a carrier of mobile multimedia, whose functions contain network, music, films, information, pictures, etc. Nowadays, mobile multimedia has been used in teaching widely, such as the application of smartphone mobile multimedia in the teaching of badminton and English, and the quality-oriented education [4]. The main purpose is to create a certain classroom climate, set a specific teaching situation, and fully motivate students' interest in learning by computer mobile multimedia technology in order to improve the teaching effect [5]. Mobile devices can be named as PDA, palm computer, WAP phone, smartphone, etc. The main mobile device is mobile phone and the mobile phone operating systems are Symbian, Palm, Linux and Mobile. Among 
those, Symbian system is flexible and valid and is supported by many mobile phone manufacturers, that has great superiority [6]. Taking Symbian OS as the supporting platform for multimedia development, the development of its application has practical significance and market prospect.

\section{State of the art}

In the evolution of the physical teaching methods in China, the mobile multimedia teaching method has replaced the traditional teaching methods gradually. Among all sports, gymnastics has been popular among teachers and students since it appeared in Chinese physical education curriculum in 1980s [7]. Gymnastic movements include the movements of upper limbs, body and lower limbs. To finish a full set of movements, the limbs and the body shall be coordinated. In the past gymnastics teaching, teachers should demonstrate and explain the gymnastic movements one by one and they mainly focused on correcting students' movements. Moreover, the teaching time was limited, so that students' learning effect couldn't meet the expected teaching objectives because they couldn't practice and be guided by teachers in time after class [8]. Therefore, the application of mobile multimedia in the gymnastics teaching is an effective means to improve the teaching effect.

The experiment made by Yang showed that multimedia technology could help students to master the gymnastic movements in a short time and achieve the ideal results [9]. Wang combined the advanced audio-visual equipment with the multimedia and discovered that, the combination could stimulate students' interest in learning, cultivate their sense of rhythm, and get good learning results [10]. Stanford University put forward a micro-teaching method, which was a type of small multimedia teaching based on the modern education theory and modern educational technology that was also applied to the gymnastics teaching [11]. Japan was the first country to apply multimedia teaching in physical education based on CAI (Computer Assistant Instruction) schema and combined with the local area network, campus network and internet, and finally achieved good teaching effect in a series of teaching experiments [12]. At present, as a developing country, China's multimedia technology is being popularized in teaching. Moreover, there are some deficiencies. Firstly, the equipment is carried inconveniently and usually the gymnastics teaching is implemented in outdoors or in gymnasiums. But there is no multimedia device in most of these places. It is not feasible to combine gymnastics with the gymnastics teaching. Therefore, in most cases, teachers still take the traditional teaching methods for gymnastics teaching and the expected teaching effect is still not achieved. Secondly, if students obtain the limited knowledge in the classroom only, they cannot meet the requirements of the social development and competition. Therefore, they need to gather new knowledge, methods, new theories and new information in different fields through various ways and channels. Nowadays, as an important educational form in the modern society, private teacher also will be certainly developed to the diversified directions from a traditionally single form. This will gradually be able to drive the educational development. In this research, we put forward to establish a mobile multimedia software platform for 
gymnastics based on Symbian OS which means to take Symbian OS as a teaching system customized for mobile devices in order to solve the problems on the multimedia application during the process of gymnastics teaching and realize the teaching effect. This system consumes less power and has good connectivity and expansibility and therefore, it is very suitable for mobile devices with small size and strong function. Moreover, this mobile multimedia platform is based on $4 \mathrm{G}$ internet including the video displaying system, database, client and server based on $4 \mathrm{G}$ with the improved P2P network model.

\section{$3 \quad$ Model analysis}

This mobile multimedia software platform for gymnastics is constructed mainly based on the improved P2P network model. For example, it can help students to learn online with their computing power and the application of Symbian OS for gymnastics software; teachers can guide students online and answer students' questions at any time.

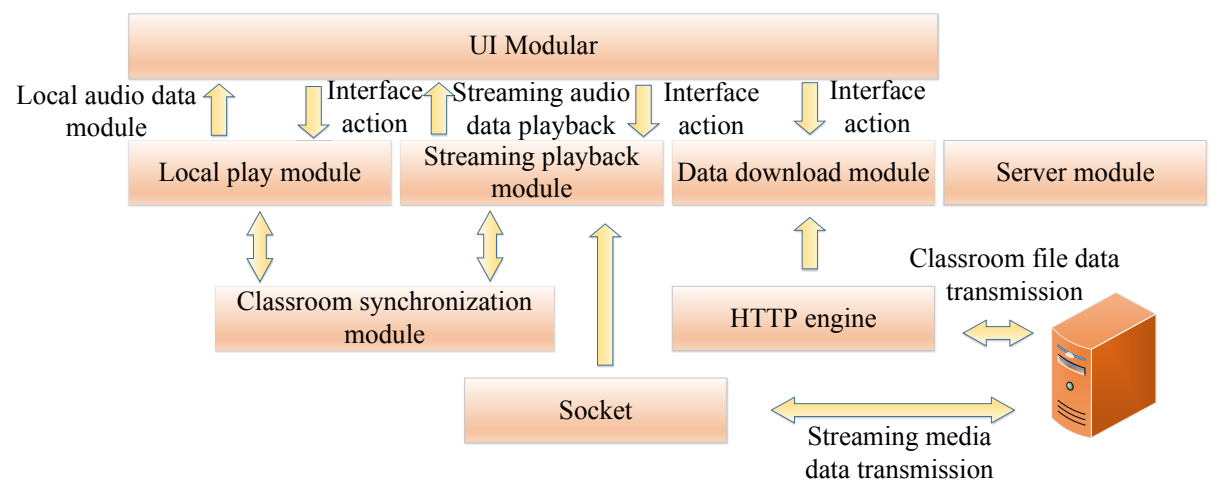

Fig. 1. Technical mode of the Distributed Hash Table (DHT)

As shown in Fig.1, we mainly took the Distributed Hash Table (DHT) for P2P model in this research. All nodes in DHT don't need to maintain the information of the whole network and only the information of the adjacent successor nodes need to be stored in the nodes. Therefore, less routing information can arrive at the goal nodes effectively. Meanwhile, the Flood Fill Algorithm is cancelled. This model can effectively reduce the pieces of node information sent to improve the expansibility of P2P network.

\subsection{The application of wireless package switch technology}

Usually, the wireless mobile communication system we use includes the two communication devices of both communication parties. Engineers must pay attention to the application of the wired communication network technology, not only the radio 
wave is needed for the communication between the two devices in order to ensure the complete operation of the wireless mobile communication system, , but also, such as the public data network (PDN), integrated service digital network (ISDN) and public switched telephone network (PSTN). Because of the fluctuant bandwidth, high bit error rate and other defects of the wireless network, the dissemination quality of the multimedia information in the wireless network is much less than that in the wired network. The key to improve the quality of the mobile communication system is how to improve the transmission technology of the wireless network in the communication system, and people mainly use radio wave technology to disseminate information in the wireless network transmission technologies.

We used the wireless package switch technology to improve the quality of the wireless network information transmission technology. The wireless package switch technology mainly contains GPRS and CDMA which can guarantee the quality of the end-to-end information transmission in the wireless network and the wireless IP connection in the wide area network. GPRS network communication mode is a type of new multilayer mobile data transmission business based on the existing CSM technology. It can guarantee the stability of data transmission effectively due to its high maturity, large scale, small coverage, rich terminal products and other features. At present, there is only one GPRS network access way for the GSM network technology and it has been applied in the world which limits the diversity of information transmission modes in the network communication. About the way to transmit information in the wireless network, GRRS is taken for both CMWAP and CMNET as the transport protocol. But they are different to some extent due to different access ways and location. The wireless network of CMWAP is partly limited compared to that of CMNET, and their network expenses also are different. When a mobile device visits the external network with a network address translator (NAT) by CMNET wireless network transmission technology, the wireless network of CMNET is transmitted by the third layer in TCP/IP network hierarchical model, a transport layer. The mobile devices connected based on this wireless network own the ability to visit internet completely, but this way has no limits on UDP and TCP. Compared to that, the mobile devices applying wireless network of CMWAP visit the external network by WAP gateway, and WAP gateway is on the forth layer in TCP/IP network hierarchical model, an application layer. However, the application layer of this model only can realize the function of HTTP proxy but cannot realize the gateway functions of NAT, route and local area network, which decide that its application is greatly limited. Therefore, the wireless package switch technology can effectively improve the quality of information transmission by wireless network.

\subsection{The audio editing interfacing based on Symbian MMF}

The audio editing interface we know is mainly composed of MMda Audio Player Callback and CMda Audio Player Utility, which supports the audio editing formats such as WAV, AMR and MP. MMda Audio Player Callback is used to inform the client of the sample initialization and finished playing and CMda Audio Player Utility is used to set the volume, upload and play the audio. In order to get a better audio 
playing effect, we used MMda Audio Player Callback to design the player mainly. This design strategy contained an object of CMda Audio Player Utility to control playing. The music player is divided into six modules in functions: (1) UI module, which is used to switch the interface display and interfaces and handle the keys pressed by users; (2) local playing module, which is used to play the local audio files and control the volume; (3) streaming playing module, which is used to realize the interaction with the server and streaming playing; (4) data download module, which is used to download and sore the audio data; (5) lyrics sync module, which is used to guarantee the synchronous playing of audio lyrics; (6) server module, which is used to provide music files, lyrics and other download resources.

The relations between different modules are as shown in Fig.2, and the class diagram of the audio editing player is as shown in Fig.3.

By the audio editing technology, firstly we created a player and loaded some specified audio files and then initialized it. If the player is initialized successfully in this routine, Symbian MMF will invoke the function, Mapc Init Complete ( ) to inform the player. After receiving the order, the player will invoke Play ( ) to play the audio file specified in advance normally. In the playing process, we can adjust the volume and suspend, advance and retreat the audio file on the player. After the specified audio file is played completely, MMF player will invoke the function, Mapcplay Complete ( ) to close the file. If an abnormal condition occurs during playing process, MMF will invoke Mapcplay Complete ( ) to adjust the conditions of the player correspondingly. For example, When the player's loudspeaker is occupied by higher applications (phone rings), the player will stop playing. The specific playing process is shown in Fig.4.

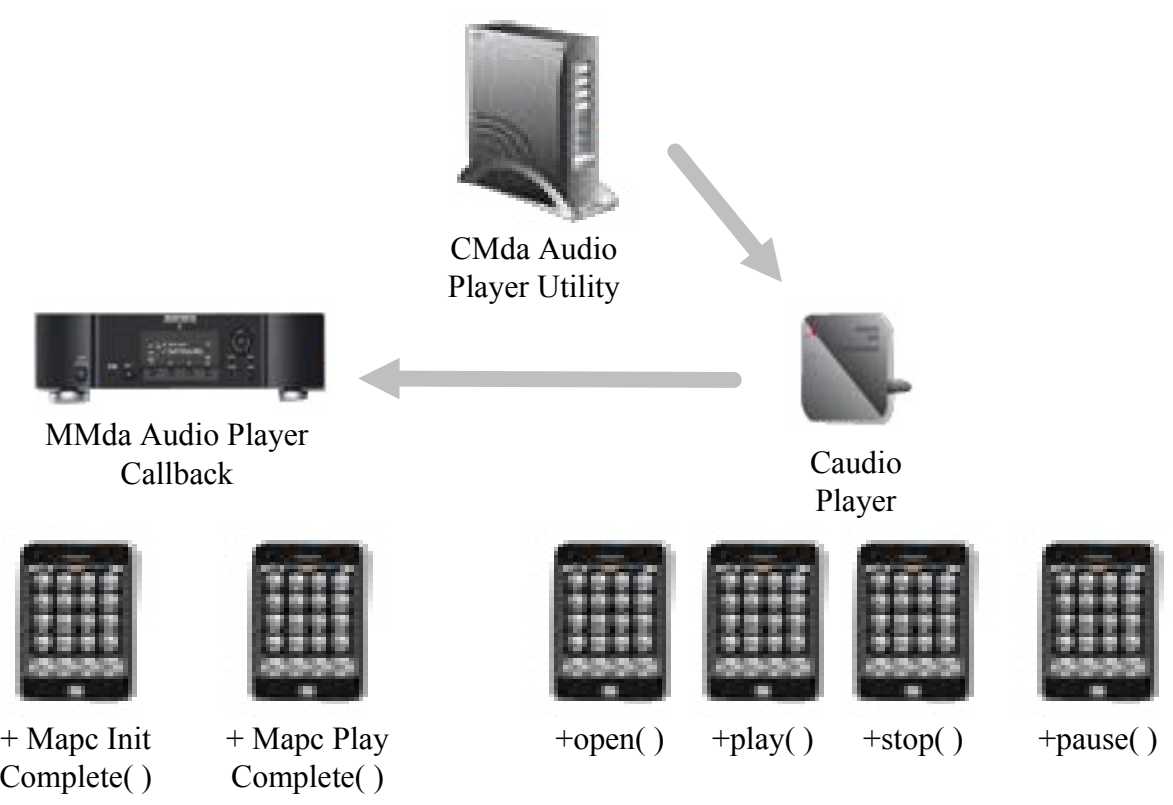

Fig. 2. Functional relation diagram of the music player 
Paper-Symbian OS for Developing Mobile Multimedia Software Platform for Gymnastics

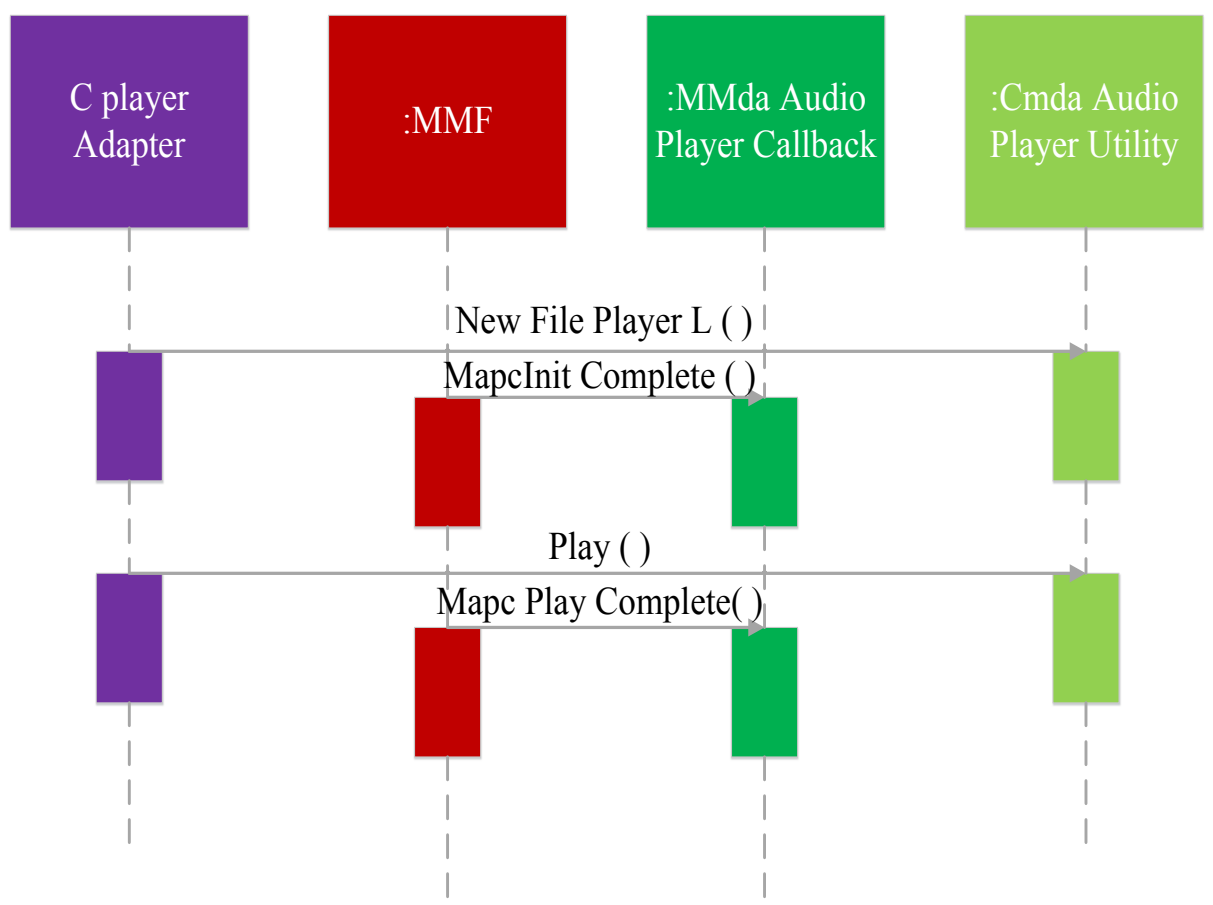

Fig. 3. Class diagram of the audio editing player

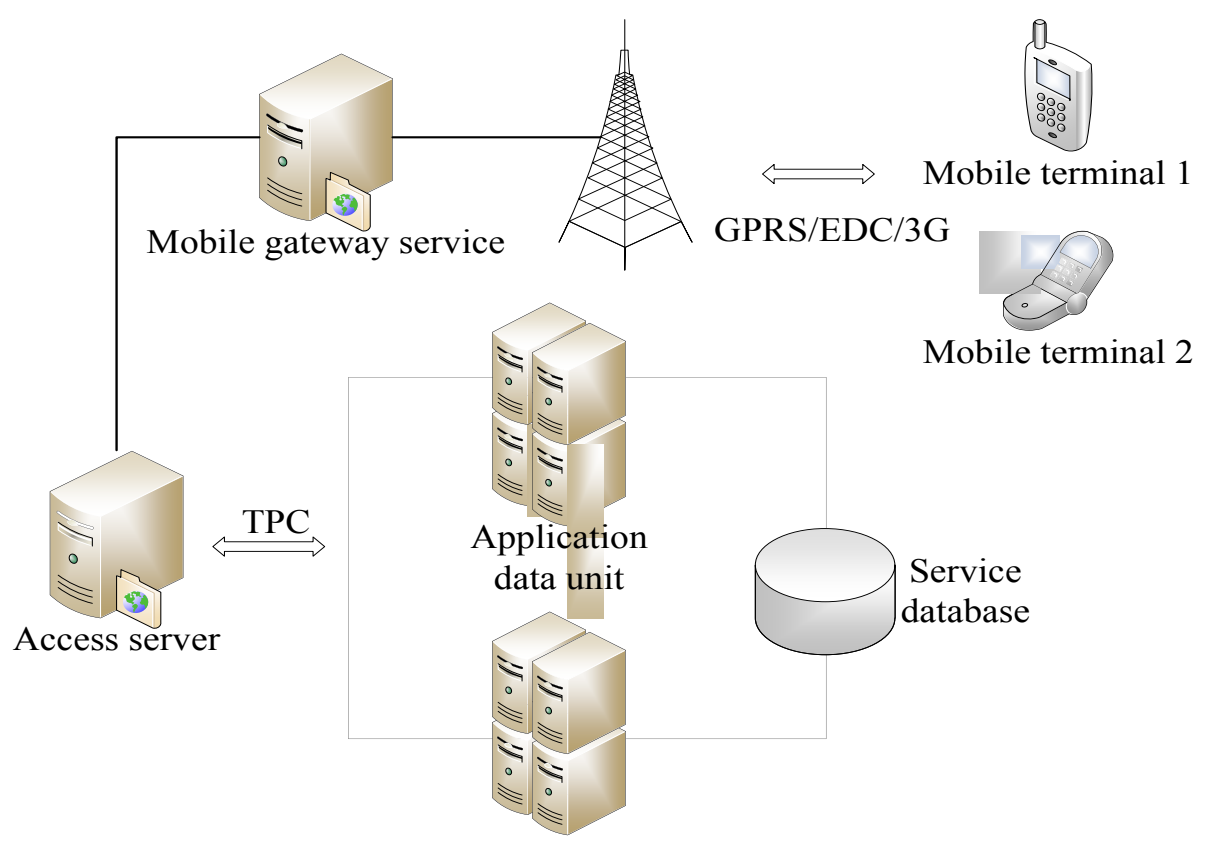

Fig. 4. Playing process diagram of Symbian MMF 
Firstly, we prepared an audio file for playing in order to make the player play a file while downloading another file. While the audio was being playing, the player would download another audio file automatically online. After the audio was played completely, the player would open the file downloaded immediately. Therefore, as long as the network transmission speed is faster than the audio playing speed, the player can play audio files uninterruptedly.

Before MMF player doesn't invoke Mapc Init Complete () of the error code, KErr None, it cannot invoke Play (), Set Volume () and other functions, otherwise a gross error will occur.

\section{Construction of mobile multimedia software platform for Gymnastics based on Symbian OS}

\subsection{Overview of multimedia design}

The portability of mobile phones, the limited hardware and memory, insufficient processing capacity of CPU and other defects limit the processing capacity on big files. As the resources of multimedia software, usually the size of pictures, audios, videos and other files are large. Therefore, how to operate the large files is the key point to improve the running speed of software. To solve such problems, the multimedia software we researched and developed has the functions of synchronous downloading and playing, so that the mobile multimedia software operates solely not as the stand-alone software. We set that the multimedia resources needed by users would be transmitted real-timely through the wireless network from the internet server and be played smoothly on the mobile phone. Another key point to realize this design is to guarantee the fluency of the wireless network. However, because the existing GPRS bandwidth speed is limited, it can meet the transmission requirements of pictures and audio resources only. At present, the peer-to-peer network connection mode used widely on internet is not suitable for mobile phones, because two phones cannot be connected directly by GPRS. The platform we designed and developed will take the client/server mode (client/server is called $\mathrm{C} / \mathrm{S}$ for short). The overall structure model of the system is shown in Fig.5.

We took the modularized design pattern to provide convenience for the future expansibility and technical service of the multimedia client platform. With the basic principle of tightening the cohesion and loosening the coupling, the platform is mainly divided into four parts: media playing module, UI module, data memory module, and network communication module as shown in Fig.6.

The main functions of the four modules are as follows:

1. Playing module: the player based on Symbian MMF software can provide two audio playing programs, both of which can control the playing of MP3, AMR and other common audio formats. In this article, we introduced the function the synchronous playing and downloading emphatically. 
2. UI module: this module is mainly used to distribute the user interface including displaying the pictures and characters in the file and processing the playing keys.

3. Network communication module: the account takes charge of communication process between the player and the internet server. In this module, in order to guarantee smooth playing, a Socket communication program is supplied including connection establishment, communication format design and data acceptance and processing.

4. Data memory module: this module is mainly used to manage file fluidization and memory space and take encipherment protection for files.

Among these four modules, the designer focused on the design of the media playing module and network communication module.

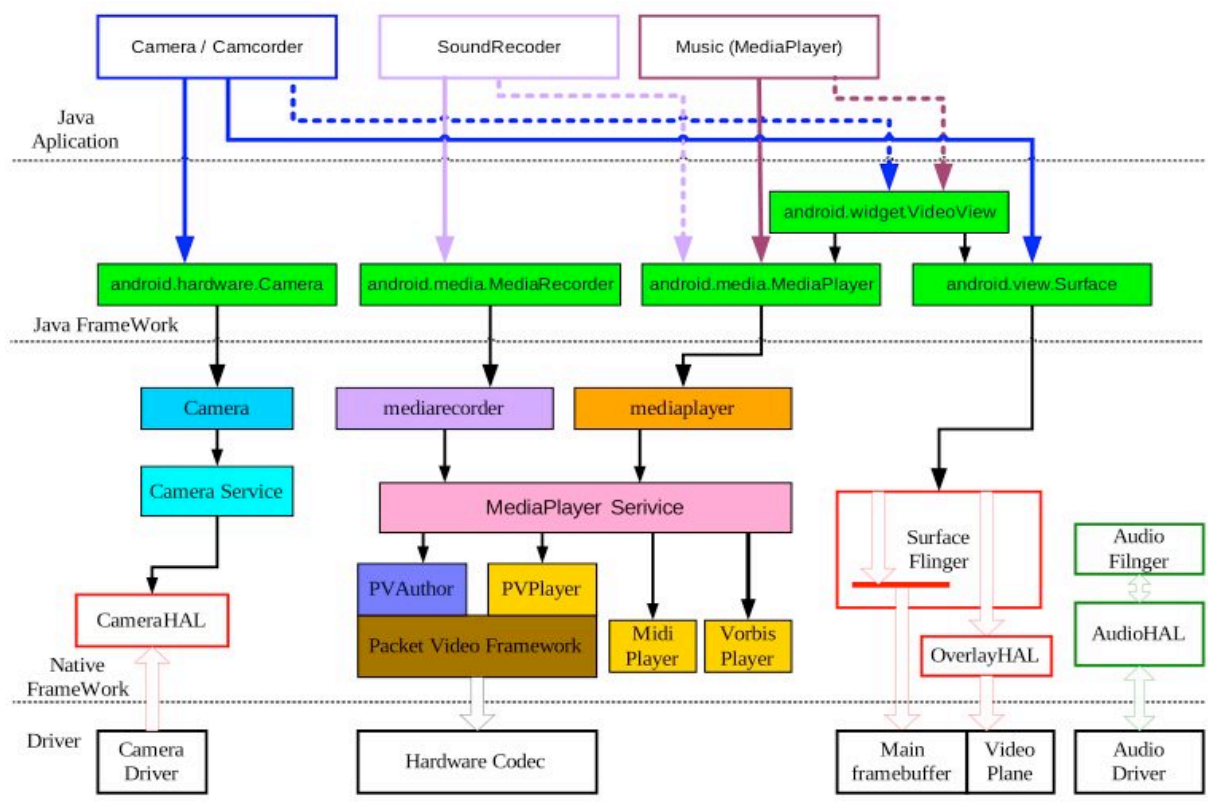

Fig. 5. Overall structure chart of the mobile multimedia software platform

Mobile multimedia application software

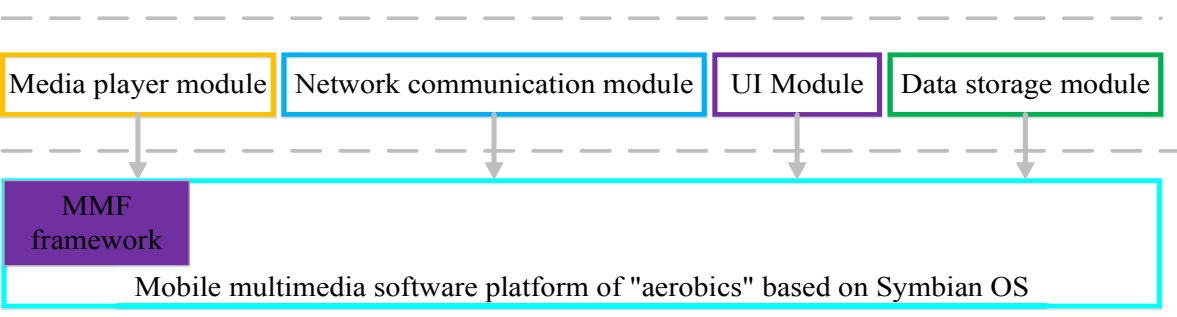

Fig. 6. Structure chart of the client platform 


\subsection{Analysis of the teaching effect of the mobile multimedia software platform for Gymnastics based on Symbian OS}

We selected 40 gymnastics trainees from the gymnastics major of a physical culture institute in a university and then applied the multimedia teaching platform we researched and developed for them. The login interface of the multimedia software platform for online learning is shown in Fig.7, on which, teachers and students can $\log$ in the platform after keying their job numbers or student numbers. The beginning interface of the teaching model is shown in Fig.8, mainly includes the learning unit, courseware, learning activities, files and the learning test module. After taking a questionnaire survey, visiting the trainees and collecting their opinions, the results are provided in Fig. 7 and Fig. 8 as well as in Table 1 and Table 2.

By comparing the data in the above two tables, we can draw a conclusion that the trainees having used the multimedia platform had deeper understanding of gymnastics and the multimedia platform could help the trainees to improve their skills. After survey, the trainees used the platform more and more frequently.

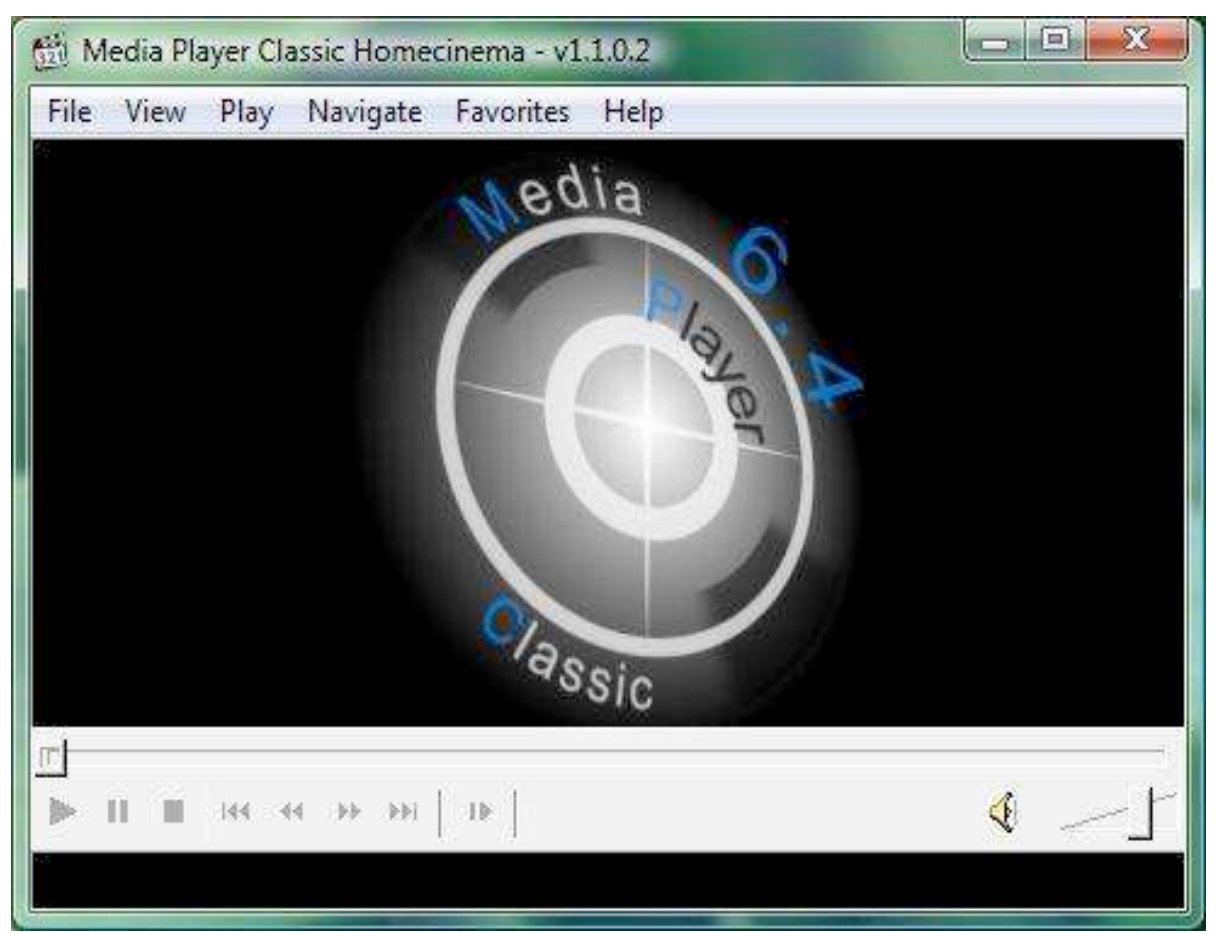

Fig. 7. The login interface 


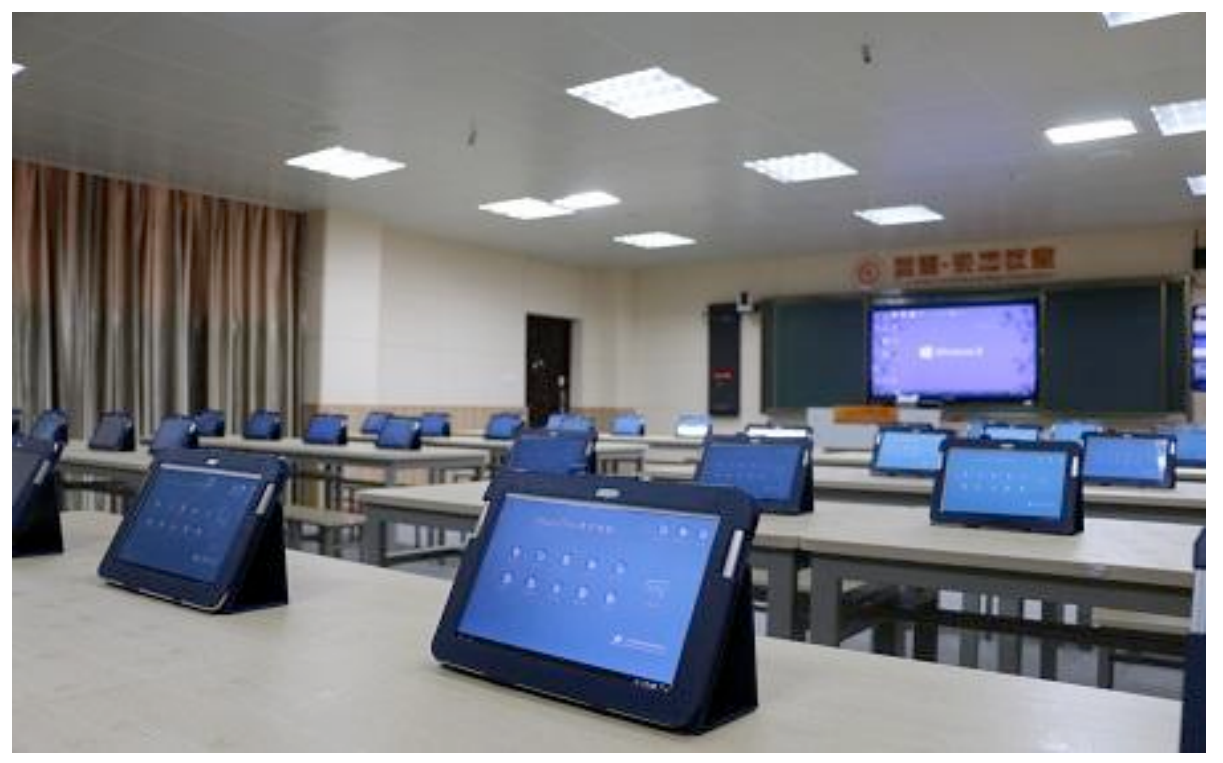

Fig. 8. Choice interface of the curriculum module

Table 1. The effect of multimedia technology in the experimental group $(\mathrm{N}=40)$

\begin{tabular}{|l|c|c|c|}
\hline \multicolumn{1}{|c|}{ Survey content } & Frequent & Occasional & No \\
\hline Browse the content of the public platforms (\%) & 60.87 & 39.13 & 0 \\
\hline Communicate with other by Wechat or QQ (\%) & 82.61 & 17.39 & 0 \\
\hline $\begin{array}{l}\text { Watch and analyze the videos about the gymnastics standards and them- } \\
\text { selves }\end{array}$ & 69.57 & 30.43 & 0 \\
\hline
\end{tabular}

Table 2. The statistics of the evaluation of students in the experimental group on the effect of multimedia teaching $(\mathrm{N}=40)$

\begin{tabular}{|l|c|c|c|c|}
\hline \multicolumn{1}{|c|}{ Survey content } & Agreed very much & Agreed & Ordinary & Not agreed \\
\hline $\begin{array}{l}\text { The content of the public platforms has improved } \\
\text { their understanding and mastery of knowledge on } \\
\text { aerobics. }\end{array}$ & $26.13 \%$ & $39.78 \%$ & $34.09 \%$ & 0 \\
\hline $\begin{array}{l}\text { The relationships among them and the teachers } \\
\text { and schoolmates become harmonious by network } \\
\text { learning. }\end{array}$ & $30.48 \%$ & $43.09 \%$ & $26.43 \%$ & 0 \\
\hline $\begin{array}{l}\text { Their gymnastics skill has been improved by } \\
\text { video recording. }\end{array}$ & $30.43 \%$ & $47.74 \%$ & $21.83 \%$ & 0 \\
\hline $\begin{array}{l}\text { This teaching method shall be continued to use in } \\
\text { the future study necessarily. }\end{array}$ & $39.13 \%$ & $52.70 \%$ & $8.17 \%$ & 0 \\
\hline
\end{tabular}




\section{Conclusions}

The mobile multimedia software for Gymnastics based on Symbian OS is designed and developed in this research. This can guarantee the network transmission quality to the client by the wireless package switch technology and improve the smooth operation of the client software based on the audio editing interfacing of Symbian MMF. A survey shows that the experimental group had higher satisfaction with application of this platform software and the software could improve their gymnastics skills. The advantages of the platform are as follows: firstly, students can master the full set of the gymnastics movements and more perfect details with the immediacy of the mobile video. Secondly, the resources are more abundant in the constrained learning environment. Thirdly, the interaction is stronger: by network courseware, real-time and visually interactive teaching and phonetic explanation, students can realize interactive learning real-timely, and teachers can answer students' questions in learning correctly in details. Meanwhile, the software is not limited by time and space, so that users can use the time more efficiently to improve the learning efficiency greatly. Moreover, it can further reduce teachers' workload for preparing lessons, help teachers to transfer the focus on learning from teaching, and provide a personalized, friendly and easy-touse learning interface.

To sum up, the gymnastics software platform built based on Symbian OS takes multimedia. Students' effectiveness evaluation after using and all research indexes achieved the expected effect basically. Therefore, the experiment is feasible and superior and this platform can be applied in the gymnastics teaching. It's worth noting that the multimedia technology just supplements the traditional teaching advantageously and the teachers shall absorb the essence of multimedia teaching based on the advantages of the traditional gymnastics teaching and combine both of them organically, so that they can display their respective advantages and complement each other to achieve the ideal application effect.

\section{References}

[1] Vrana, R. (2013). Promotion of Scientific Literacy and Popularization of Science with Support of Libraries and Internet Services. Communications in Computer \& Information Science, 397: 324-330. https://doi.org/10.1007/978-3-319-03919-0 42

[2] Hoque, M.A., Siekkinen, M., Nurminen, J.K., Aalto, M., \& Tarkoma, S. (2015). Mobile multimedia streaming techniques: QoE and energy saving perspective. Pervasive and Mobile Computing, 16:96-114. https://doi.org/10.1016/j.pmcj.2014.05.004

[3] Lv, Z., Chirivella, J. Gagliardo, P. (2016). Bigdata Oriented Multimedia Mobile Health Applications. Journal of Medical Systems, 40:1-10. https://doi.org/10.1007/s10916-016$\underline{0475-8}$

[4] Liu, S., Sun, L.N. (2014). Application of Multimedia Technology in Experiment Teaching of Environmental Engineering Microbiology. Applied Mechanics \& Materials, 596:10261029. https://doi.org/10.4028/www.scientific.net/AMM.596.1026

[5] Huang, Z.P. (2005). The Applying of Multimedia Technology in Education in Party Lecture Teaching. Journal of Fujian Normal University, 21:107-111. 
[6] Riva, O., \& Toivonen, S. (2007). The DYNAMOS approach to support context-aware service provisioning in mobile environments. Journal of Systems and Software, 80:1956-1972 https://doi.org/10.1016/j.jss.2007.03.009

[7] Law, M.P., Côté, J., \& Ericsson, K.A. (2007). Characteristics of expert development in rhythmic gymnastics: A retrospective study. International Journal of Sport and Exercise Psychology, 5:82-103 https://doi.org/10.1080/1612197X.2008.9671814

[8] Jing, G.H., Sun, D.F. Zheng, Y. (2005). Research on the Changes and Set-up of Gymnastics Teaching Materials for PE-Majors of General Universities. Journal of Beijing University of Physical Education, 28:385-387

[9] Yang, Y.X. Application of multimedia technology in Aerobics Teaching in Higher Vocational Colleges. Science \& Technology Information, 2009, vol. 36, pp. 197-197.

[10] Wang, H.X. (2009). The experimental research of "audio visual strengthening rhythm training method" in Aerobics Teaching of College Students. Journal of Wuhan Institute of Technology, 31:88-90

[11] Fernández, M.L. (2005). Learning through microteaching lesson study in teacher preparation. Action in Teacher Education, 26:37-47 https://doi.org/10.1080/01626620. 2005.10463341

[12] Nagata, N. (1997). The Effectiveness of Computer - Assisted Metalinguistic Instruction: A Case Study in Japanese. Foreign Language Annals, 30:187-200. https://doi.org/10.1111/ j.1944-9720.1997.tb02341.x

\section{Authors}

Yingbao Zhou is a Lecturer with the School of Department of Physical Education, Nanjing Xiaozhuang University, Nanjing 210028, China. His research interests include physical education and sports exercise. (zhouyb111@yeah.net).

Article submitted 06 June, 2017. Published as resubmitted by the author 07 August 2017. 